\title{
Expressão das óxido nítrico sintetases na vasculopatia coronariana do transplante cardíaco
}

\author{
Fernanda VIARO \& Paulo Roberto B. ÉVORA*
}

RBCCV 44205-487

\begin{abstract}
Viaro F \& Évora PRB - Expressão das óxido nítrico sintetases na vasculopatia coronariana do transplante cardíaco. Rev Bras Cir Cardiovasc 2000; 15 (1): 55-65.

RESUMO: A maior complicação que pode limitar a evolução a longo prazo de um transplante cardíaco é o desenvolvimento de doença arterial coronariana. Esta forma de doença coronariana é distinta da doença coronariana aterosclerótica de pacientes não submetidos a transplante cardíaco. Evidências atuais, obtidas mediante a ecografia intravascular, demonstraram que a ocorrência de uma disfunção endotelial precoce, principalmente mediada pela expressão da isoforma induzível da óxido nítrico sintetase (iNOS) e associa-se com desenvolvimento de aterosclerose no aloenxerto durante o primeiro ano após o transplante. Esta revisão foi elaborada começando pelos conceitos básicos (descrição da enzima NOS e suas isoformas conhecidas; breve comparação entre elas), revisando-se, na seqüência, a disfunção endotelial coronariana pós-transplante cardíaco do ponto de vista específico da função enzimática da NOS. No transplante cardíaco a iNOS promove rejeição aguda, mas previne a crônica. A relação entre estes efeitos completamente opostos permanece desconhecida, sabendo-se que são mecanismos diferentes dependentes do tempo.
\end{abstract}

DESCRITORES: Síntese de óxido nítrico, metabolismo. Endotélio vascular, enzimologia. Transplante do coração, fisiologia. Rejeição de enxerto, enzimologia.

\section{INTRODUÇÃO}

A maior complicação que pode limitar a evolução a longo prazo de um transplante cardíaco é o desenvolvimento de doença arterial coronariana (DAC) (1). Esta forma de doença coronariana é distinta da doença coronariana aterosclerótica de pacientes não submetidos a transplante cardíaco. A doença coronariana em corações transplantados parece começar nos vasos distais, progredindo proximalmente. É encontrada raramente próxima a bifurcações dos vasos epicárdicos maiores e, portanto, não é fácil de ser tratada por angioplastia percutânea ou, mesmo, por revascularização cirúrgica do miocárdio. Esta forma de aterosclerose coronariana é clinicamente silente, por causa do estado denervado do coração trans- plantado, apresentando-se como disfunção ventricular esquerda ou arritmia na ausência de angina do peito. Uma coronariografia rotineira anual é, em geral, necessária para o seguimento desta complicação. Histologicamente, estes vasos têm um estreitamento fibroso concêntrico sem o padrão da clássica placa aterosclerótica excêntrica. A maioria dos pacientes transplantados mostram evidências de DAC dentro de três anos. Embora a causa desta situação não seja clara, ela representa, provavelmente, uma rejeição vascular crônica no meio do ambiente aterogênico (hipertensão, hipercolesterolemia, etc.). O tratamento não previne o desenvolvimento desta complicação, que é a maior causa para a consideração de retransplante nos primeiros seis meses do pós-operatório. Evidências atuais, obtidas mediante a ecografia

\footnotetext{
Trabalho realizado na Faculdade de Medicina de Ribeirão Preto da Universidade de São Paulo. Ribeirão Preto, SP, Brasil.

* Da Faculdade de Medicina de Ribeirão Preto da USP.

Recebido para publicação em outubro de 1999.

Endereço para correspondência: Paulo Roberto B. Évora. Rua Rui Brabosa, 367, Apto 7. Ribeirão Preto, SP, Brasil. CEP 14015-120. Tel: (016) 636-4149. Fax: (016) 610-9890.e-mail: prbevora@keynet.com.br
} 
intravascular, demonstraram que a ocorrência de uma disfunção endotelial precoce, principalmente mediada pela expressão da isoforma induzível da óxido nítrico sintetase (iNOS) e associa-se com desenvolvimento de aterosclerose no aloenxerto durante o primeiro ano após o transplante (2).

Um trabalho ítalo-americano examinou 39 aloenxertos cardíacos colocados durante mais de 2 meses e 37 enxertos durante 2 meses, realizando uma série de observações relacionadas com a vasculopatia pós-transplante: 1) A vasculopatia do aloenxerto afeta a todas as camadas das artérias coronárias epicárdicas e, geralmente, as artérias coronárias intramurais da metade externa da parede ventricular esquerda. 2) A lesão da íntima resultante é relativamente uniforme, e constante principalmente em tecido fibroso celular e acelular; é difusa e afeta a todos os segmentos das artérias coronárias epicárdicas maiores e menores. 3) O grau de estreitamento luminal resultante é similar na maioria dos segmentos coronários de $5 \mathrm{~mm}$, o que torna arriscado prever com confiança o grau de estreitamento luminal mediante uma angiografia coronária. 4) A extensa fibrose adventícia e a intensa infiltração de tecido fibroso subepicárdico, provavelmente, inibem a dilatação e a remodelação das artérias coronárias epicárdicas e, sem dúvida, as pode comprimir. 5) O estreitamento luminal das artérias coronárias epicárdicas após o transplante pode ser conseqüência tanto das lesões intraluminais como da compressão exterior do tecido fibroso circundante. 6) Se observa com freqüência trombo intraluminal e intralesão, assim como canais multiluminais nas placas coronárias, o que sugere que a organização dos trombos desempenha certo papel na progressão da CAD epicárdica pós-transplante. 7) As lesões coronárias que se formavam após o transplante cardíaco têm uma composição morfológica muito diferente das que aparecem na aterosclerose natural (sem transplante). 8) Os infiltrados inflamatórios celulares são freqüentemente extensos nos tecidos subepicárdicos, e os infiltrados nesta área podem ser extensos, inclusive quando os infiltrados inflamatórios miocárdicos intersticiais são mínimos ou ausentes (3).

O produto da óxido nítrico (NO) sintetase é o mais potente vasodilatador endógeno conhecido. $\mathrm{O}$ $\mathrm{NO}$ além de ser um potente vasodilatador e inibidor da adesão e agregação plaquetárias, reduz a aderência de leucócitos ao endotélio vascular, e, também suprime a proliferação de células da musculatura lisa vascular por inibição de fatores de crescimento (4). A importância fisiológica deste fator endotelial tem sido demonstrada em animais e humanos. Administração de inibidores da NOS eleva a pressão sangüínea devido a um aumento na resistência vascular sistêmica $(5,6)$. Inúmeras anormalidades fisiopatológicas estão associadas à sín- tese reduzida e/ou aumento da degradação do NO vascular. Estas incluem, entre outras, a hipercolesterolemia, o diabete melito, a hipertensão arterial e o tabagismo (4). Portanto, o conhecimento das NO sintetases (NOS), a enzima responsável pela produção do NO, é de extrema importância científica, não só para o entendimento de novos mecanismos fisiopatológicos, mas, também, por ser um alvo para a descoberta de novas intervenções terapêuticas, incluindo a DAC pós-transplante (7).

O propósito deste texto é o de revisar o papel das NOS nos mecanismos fisiológico e fisiopatológico do sistema cardiovascular. O texto inclui uma síntese dos conceitos básicos (descrição da enzima NOS e suas isoformas conhecidas, além de uma breve comparação entre elas), revisando-se, na seqüência, a disfunção endotelial coronariana póstransplante cardíaco do ponto de vista específico da função enzimática da NOS e, finalizando, com comentários adicionais pertinentes ao assunto.

\section{CONCEITOS BÁSICOS}

As óxido nítrico sintetases (NOSs), do ponto de vista bioquímico, são uma família de enzimas complexas que catalisam a oxidação da L-arginina para formar óxido nítrico e L-citrulina. Elas são melhor caracterizadas como citocromo hemeproteínas semelhantes ao citocromo P-450 que dependem de cofatores como: oxigênio molecular, NADPH, flavinas e tetrahidrobiopterin. As três formas humanas de NOS identificadas até agora, ecNOS (constitutiva endotelial ), nNOS (neuronal) e iNOS (induzida), são encontradas nos cromossomos humanos 7, 12 e 17, respectivamente ${ }^{(8)}$, assim foram nomeadas com base nos tecidos nos quais foram primeiro clonadas e caracterizadas (4).

Óxido nítrico sintetase constitutiva ou endotelial (ecNOS) - O papel do NO na regulação do tônus vascular e da função plaquetária é atribuído à atividade da forma constitutiva endotelial da NOS. Inativação da ecNOS limita a contribuição do NO na homeostase dos vasos e resulta num aumento do tônus vascular e da adesão e agregação plaquetárias. A via de transdução de sinal que leva à ativação da ecNOS, no seu curso completo, começa com a estimulação de um receptor de membrana, que ativa uma G-proteína acoplada à fosfolipase C. Esta enzima regula a via fosfatidilinositol gerando inositoltrifosfato $\left(\mathrm{IP}_{3}\right)$ a partir de fosfatidilinositol 4,5bifosfato (PIP2) e diacilglicerol (DAG). O IP 3 media a liberação de cálcio do retículo endoplasmático e - DAG media a entrada de cálcio extracelular. A elevação na concentração do cálcio intracelular leva à formação do complexo cálcio-calmodulina, que ativa a ecNOS, resultando na produção de NO. Essa 
cascata de eventos pode ser desencadeada por duas classes de agonistas: os dependentes ou os independentes de receptores de membrana. Agonistas dependentes de receptores como a acetilcolina, a adenosina difosfato (ADP), a serotonina, a norepinefrina e a histamina, ativam a via de transdução de sinal, pela ligação com o receptor de superfície celular específico (via completa). Agonistas independentes de receptores, atuam estimulando, seletivamente, vários componentes na via de transdução de sinal, levando à ativação da ecNOS. O fluoreto de sódio ativa a G-proteína, fosfolipase $\mathrm{C}$ ativa a via fosfatidilinositol, e o ionóforo do cálcio estimula a liberação de $\mathrm{Ca}^{++}$do retículo endoplasmático ${ }^{(9)}$ e são, portanto, agonistas independentes de receptores. Portanto, a atividade da ecNOS é regulada pela concentração de cálcio livre intracelular e pelo complexo $\mathrm{Ca}^{++}$-calmodulina (10) (Figura 1).

A ecNOS é uma proteína expressa de maneira constitucional associada predominantemente à fração subcelular, sugerindo que a enzima nativa é uma proteína componente da membrana. Recentes análises detalhadas da associação da ecNOS com a membrana celular mostraram que esta enzima está localizada no Complexo de Golgi, bem como em estruturas específicas na membrana identificadas como cavéolas. A associação da ecNOS com uma região da membrana plasmática, na qual estão concentradas várias chaves dos complexos de transdução de sinal (como G-proteínas), provavelmente tem profunda repercussão na atividade enzimática, bem como, na sua acessibilidade aos

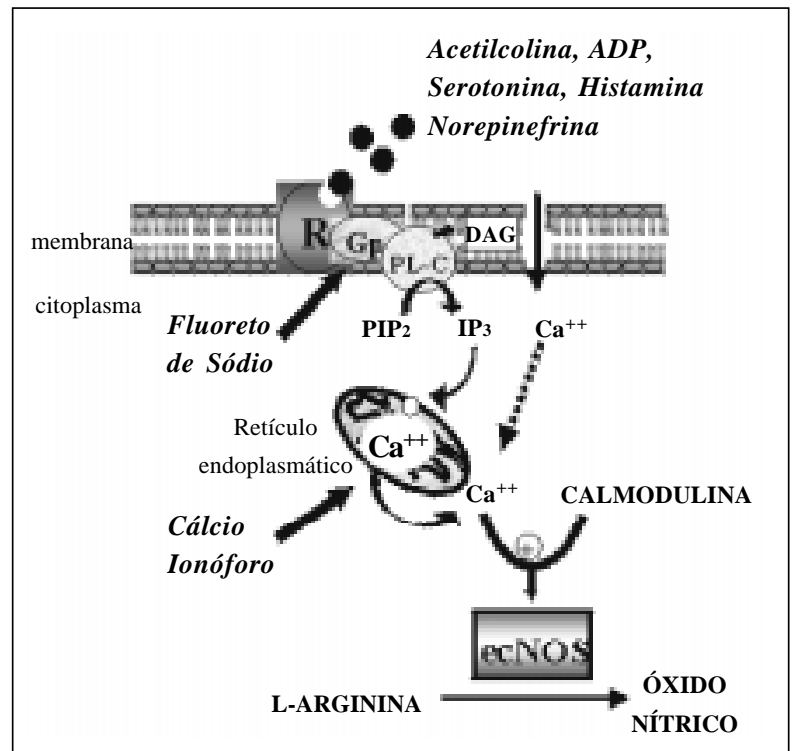

Fig. 1 - Via de liberação do óxido nítrico (NO);PIP2 = fosfatidilinositol 4,5-bifosfato; IP3 = inositoltrifosfato; ecNOS = óxido nítrico sintetase endotelial constitutiva. processos intracelulares da via de liberação do NO, incluindo processos não associados ao aumento do cálcio intracelular (11).

Óxido nítrico sintetase neuronal nNOS - Esta isoforma está presente nas células neuronais centrais e periféricas, e, certamente em células epiteliais. Sua atividade também é regulada por $\mathrm{Ca}^{++} \mathrm{e}$ calmodulina. Suas funções incluem regulação duradoura da transmissão sináptica no sistema nervoso central, regulação central da pressão sangüínea, relaxamento do músculo liso e vasodilatação via nervos nitrérgicos periféricos. Tem sido envolvida também na morte de neurônios no acidente vascular cerebral (12).

Óxido nítrico sintetase induzível (iNOS) - A expressão desta enzima é manifestada em uma multidão de células diferentes, incluindo macrófagos, células endoteliais, células da musculatura lisa vascular e miócitos cardíacos, depois de estimulação com lipopolissacárides (LPS), citoquinas (como IL1b, TFN-a, IFN-g, IL-6) e outros. Por estas características tem importante papel em atividades antimicrobianas, antiparasitárias e antineoplásicas (13-15). Esta isoforma não é regulada pelo cálcio; ela produz grande quantidade de NO que tem efeito citostático nas células alvo parasitadas pela inibição de enzimas férricas e causando fragmentação do DNA. A indução da iNOS está envolvida na patofisiologia das doenças auto-imune e no choque séptico (12).

Devido a dificuldade encontrada pelos autores desta revisão, em relação às diferentes nomenclaturas encontradas das isoformas das NOSs, resolveu-se fazer uma tabela com as possíveis nomenclaturas dadas a cada isoforma, a fim de facilitar o entendimento e esclarecimento dos leitores do tema aqui apresentado (Tabela 1).

\section{Métodos Para o Estudo da Atividade da NOS}

Metodologia laboratorial não é a maior motivação desta revisão, mas o NO é gerado a partir da L-citrulina pela ação da NO sintetase, uma enzima codificada por três diferentes genes, e está envolvido em um crescente número de fenômenos. Assim, um breve comentário sobre metodologia pode-

TABELA 1

NOMENCLATURA DA ÓXIDO NÍTRICO SINTETASES (NOSS)

\begin{tabular}{ll}
\hline ENZIMAS & NOMENCLATURAS \\
\hline NOS endotelial & eNOS, ecNOS, cNOS, NOS III ou NOS3 \\
NOS neuronal & bNOS(brain), NOS I ou NOS1 \\
NOS induzida & iNOS, NOS II ou NOS2 \\
\hline
\end{tabular}


rá ser interessante dentro do texto. Este envolvimento pode ser documentado por: a) métodos indiretos usando espectrofotometria e métodos eletromecânicos, e; b) métodos indiretos por detecção dos efeitos do NO, incluindo a localização da NOS por imunoquímica ou hibridização in situ do mRNA, ensaios biológicos, inibição da atividade da NOS, atividade de hemeproteínas, produção de nitrato/ nitrito, L-citrulina, GMPc. Uma avaliação cuidadosa das potenciais armadilhas associadas a estes métodos indiretos antes das suas utilizações é importante para evitar erros de interpretação (16).

O conhecimento dos inibidores específicos das NOSs é de fundamental importância para ensaios farmacológicos experimentais e terapêuticos.

Inibidores inespecíficos - São aqueles que inibem tanto a ecNOS como, também, a iNOS. Sendo derivados metilados e nítricos da L-arginina, atuam por competição (17), os mais conhecidos são o LNMMA, o L-NAME e o L-NOARG. Como outro exemplo, pode-se mencionar a dimetilarginina assimétrica (asymmetric dimethylarginine - ADMA) que é um inibidor endógeno circulante da NOS. Estudos demonstraram que o nível plasmático de ADMA está positivamente relacionado com fatores de risco para aterosclerose, sugerindo-se que este antagonista endógeno da NOS possa ser um marcador de aterosclerose (18)

Inibidores específicos - Inibem especificamente a isoforma iNOS; são eles os glicocorticóides (como a dexametasona), a aminoguanidina, a L-canavanina, a N6-(1-imioetil)lisina(L-NIL) e a 2,4-diamino 6-hidróxipirimidina (17) (Figura 2).

Algumas comparações entre as atividades das

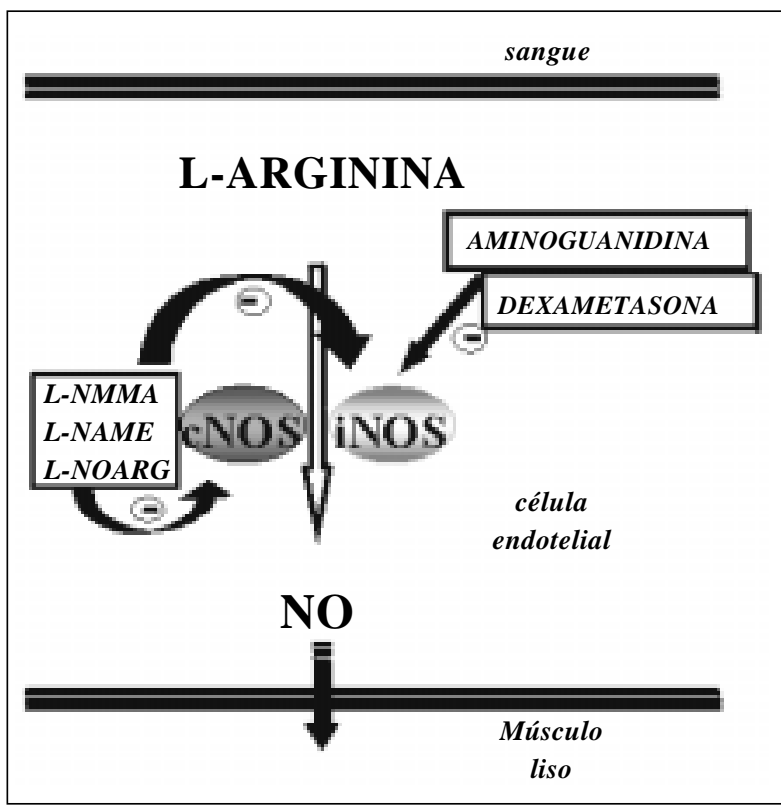

Fig. 2 - Inibidores da óxido nítrico sintetase (NOS). diferentes isoformas são dignas de apresentação dentro da proposição da discussão dos conceitos básicos. Como já foi dito, a ecNOS é uma enzima que tem sua localização associada à membrana, enquanto que as formas iNOS e nNOS são amplamente citosólicas (18). Uma outra diferença entre as isoformas da NOS é em relação à quantidade e labilidade da molécula de NO produzida. A molécula de NO é sintetizada por um curto período de tempo (segundos à minutos) quando decorrente da ativação enzimática da ecNOS ou nNOS. Em contraste, a iNOS é expressada só depois da ativação celular e então produz NO por, relativamente, um longo período de tempo (horas a dias) ${ }^{(19)}$.

\section{Distribuição Anatômica da NOS no Coração Normal}

A maior parte da atividade da ecNOS no coração está presente no endotélio ao longo da extensa rede de artérias, veias e capilares dentro do miocárdio. Esta isoforma endotelial também existe na camada endocárdica das cavidades cardíacas. A nNOS parece muito menos proeminente, embora a exata quantidade desta isoforma seja incerta no coração. Embora a iNOS não exista no coração normal, macrófagos associados a processos de remodelamento após várias formas de lesões cardíacas contêm esta isoforma. Para todas as NOS, entretanto, variações entre espécies animais e variabilidade entre modelos experimentais enfatizam a importância de estudos relacionados entre estrutura e função (20).

\section{Funções Autócrinas e Parácrinas da NOS no Coração}

Do ponto de vista das funções autócrinas e parácrinas, os diferentes tipos de células compreendendo o músculo cardíaco, expressam um ou mais das três isoformas (nNOS, ecNOS ou iNOS) da óxido nítrico sintetase.

A NOS é expressa em terminações simpáticas normais e regula a liberação de catecolaminas no coração.

A ecNOS expressas nas células endoteliais inibe o tono contrátil e a proliferação de células musculares lisas subjacentes dos vasos, inibe a agregação plaquetária a adesão de monócitos, promove um relaxamento diastólico, e diminuição do consumo de oxigênio no músculo cardíaco através de uma parácrina de NO. A ecNOS é, também, expressa de modo constitucional nos miócitos cardíacos de roedores e espécies humanas, onde ela se opõe autocrinamente à ação inotrópica de catecolaminas após estimulação muscarínica colinérgica e estimulação de receptores beta-adrenérgicos. 
A transcrição genética e a expressão proteica da iNOS, como já foi dito, são induzidas em todos os tipos de células após a exposição a uma variedade de citoquinas. À parte de participar na defesa imunológica contra microrganismos intracelulares e vírus, as grandes quantidades de NO produzidas autócrina ou paracrinamente modulam a vasoplegia e a depressão miocárdica característica da estimulação do sistema imune e promove morte celular através da apoptose. Nos miócitos cardíacos, o NO pode regular o fluxo de cálcio tipo $L$ e contração através da ativação da proteína quinase dependente do GMPc e das fosfodiesterases mediadas pelo GMPc. Outros mecanismos independentes das elevações do GMPc podem operar através da interação do NO com hemeproteínas, ferro não heme, ou resíduos livres de tiol em proteínas sinalizadoras, enzimas ou canais iônicos. Considerando-se a multiplicidade das isoformas da NOS expressas no músculo cardíaco e os potenciais alvos moleculares para o NO produzido, uma estreita regulação molecular da expressão e atividade da NOS, ao nível transcricional e pós-transcricional, parece ser necessária na coordenação de muitas das funções do NO na função cardíaca na saúde e na doença ${ }^{(21)}$.

\section{Disfunção Endotelial no Transplante Cardíaco}

Várias investigações têm mostrado a expressão da iNOS no ambiente de rejeição aguda e crônica em modelos experimentais de transplante cardíaco. Demonstrou-se que a expressão da iNOS ocorre em macrófagos infiltrantes e miócitos, durante a rejeição em corações de ratos Lewis or Wistar-Furth em receptores da raça Wistar ${ }^{(22)}$. A inibição da iNOS melhora a rejeição aguda ao transplante cardíaco. Para determinar a evolução temporal e a localização celular da expressão da iNOS durante o progresso histológico da rejeição aguda de corações transplantados em ratos, tecido de transplantes singênicos (ratos de mesma linhagem genética) e alogênicos (linhagens genéticas diferentes) foram colhidos do terceiro ao décimo dias do pós-operatório e analisados para a expressão do RNAm da iNOS. O RNAm e a atividade enzimática da iNOS foram expressos no transplante durante rejeição aguda leve, moderada e severa (do quarto ao décimo dias), mas não foram detectados em ratos normais, isogênicos ou alogênicos, antes das mudanças histológicas da rejeição aguda leve (terceiro dia do pós-operatório). A expressão da iNOS resultou no aumento sérico dos níveis de nitrito/nitrato durante rejeição leve e moderada(do quarto ao sexto dia do pós-operatório), e foram localizadas células inflamatórias mononucleares infiltrando partes do tecido transplantado durante todos os estágios da rejeição, mas não foram detectadas nas células parenquimais enxertadas, normais ou em enxertos isogênicos.
Assim, a expressão da iNOS e aumento da produção de NO ocorreram durante o estágio precoce da rejeição aguda, persistiu inalterada durante todo o processo de rejeição, e detectaram-se células inflamatórias, mas não células parenquimais enxertadas, durante todos estágios da rejeição aguda ${ }^{(23)}$. A rejeição aguda primária está associada com aumento da produção de NO nos tecidos transplantados, mas desconhece-se se isto impede ou aumenta a perda de função do enxerto. O L-NAME, um inibidor não específico da NOS, diminui a sobrevivência do enxerto de $9.4 \pm 1.5$ para $6.9 \pm 0.3$ dias. A histopatologia de corações transplantados, em assistolia, mostrou predominantemente necrose isquêmica. LNAME combinado com uma droga anti-hipertensiva

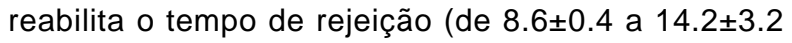
dias) e resulta numa rejeição aguda padrão. Este dado sugere que bloqueando-se a formação de NO durante a rejeição aguda de um enxerto cardíaco vascularizado resulta numa diminuição no tempo de sobrevivência do enxerto e necrose isquêmica, muito provável secundária à vasoconstrição sustentada ${ }^{(24)}$. Tratamento contínuo com aminoguanidina, um inibidor seletivo da produção de NO pela iNOS, atenuou a rejeição aguda ao transplante cardíaco. Um modelo de transplante em rato foi usado para determinar: 1) quando iNOS foi expressa no transplante de coração durante a rejeição natural aguda; 2) se a pulsoterapia com aminoguanidina atenuou as mudanças histológicas provocadas pela rejeição aguda, em comparação com os efeitos da pulsoterapia com corticóides. Neste estudo o RNAm e proteína da iNOS foram expressos durante a rejeição aguda precoce e tardia. A pulsoterapia com aminoguanidina inibiu a produção de $\mathrm{NO}$ e atenuou as mudanças histológicas da rejeição aguda, mas não efetivamente como a terapia corticóide. Concluí-se que: 1) primeiro a expressão da iNOS ocorre durante a rejeição aguda ao transplante precoce e persiste durante toda rejeição e; 2) O NO é uma importante molécula efetora na rejeição aguda. Então, inibição da NOS pode oferecer uma terapêutica auxiliar no controle da rejeição aguda (25). Evidências recentes indicam que o NO modula permeabilidade vascular sujeita a condições fisiológicas e patofisiológicas. A inibição da iNOS com aminoguanidina preveniu ou atenuou a disfunção da barreira vascular no transplante cardíaco e na circulação sistêmica e reduziu os níveis nitrito/nitrato de transplantes alogênicos para níveis semelhantes ao encontrados em transplantes isogênicos. A aminoguanidina não afetou as mudanças histológicas leves da rejeição presente nos transplantes. Este resultado mostra novas observações: 1) a função da barreira endotelial está comprometida em vasos sistêmicos, particularmente no cérebro, distante do local de rejeição ao transplante; 2) a disfunção da barreira vascular no transplante está associada com aumen- 
to da produção de NO e expressão do RNAm da iNOS nos tecidos afetados (por exemplo, pulmões nativos e corações transplantados) e; 3) a inibição da produção de NO pela iNOS previne a disfunção da barreira vascular no transplante cardíaco e vasos sangüíneos sistêmicos ${ }^{(26)}$. Um outro estudo examinou a interação de corticóides, expressão gênica e atividade enzimática da iNOS num modelo de transplante cardíaco em ratos. O aumento da produção de NO na rejeição ao enxerto foi demonstrado pela elevação nos níveis séricos de nitrito/nitrato, foram significantemente reduzidos pela pulsoterapia com dexametasona por dois dias prévios ao sacrifício animal ou pelo tratamento contínuo com dexametasona. Demonstrou-se um aumento da atividade enzimática enxerto cardíaco, o qual foi significantemente reduzido com pulsoterapia ou terapia contínua de dexametasona. O aumento da atividade enzimática da iNOS em tecidos alogênicos resultou da indução da expressão do RNAm da iNOS, que foi $99 \%$ inibida pelo tratamento com dexametasona. A pulsoterapia com dexametasona reduziu mas não eliminou as mudanças histológicas da rejeição aguda. Portanto, tratamento com corticóide resulta em inibição da expressão da iNOS durante a rejeição ao enxerto. Estes resultados demonstram que a expressão da iNOS durante rejeição aguda é imunomediada e sugere que a ação imunossupressora dos corticóides no tratamento da rejeição aguda pode incluir inibição da expressão da iNOS (27). Transplantes alogênicos em ratos Lewis foram tratados na hora do transplante com FK 506, ciclosporina $A$, dexametasona ou uma combinação das três drogas. Evidência histológica de rejeição e os níveis de RNAm e atividade enzimática da iNOS no homogenato ventricular foram significantemente reduzidas abaixo daquelas observadas no enxerto não tratado. Assim, os dados obtidos em modelos de transplantes em ratos indicam que drogas imunossupressoras reduzem o RNAm e a atividade enzimática da iNOS miocárdica na rejeição ao enxerto cardíaco. Os resultados coincidem com a hipótese de que a resposta aloimune e citoquinas liberadas estão envolvidas na expressão de iNOS durante rejeição ao transplante cardíaco (28). Usando ratos geneticamente desprovidos de iNOS como receptores num modelo de transplante cardíaco, num modelo de rejeição aguda, a iNOS foi predominantemente localizada em tecidos infiltrados por células imunológicas. No sétimo dia, enxertos em receptores deficientes da iNOS mostraram redução nos infiltrados inflamatórios e nas lesões de miócitos, resultando em significante baixa na rejeição. Em contraste, num modelo de rejeição crônica localizou-se expressão adicional de iNOS em células parenquimatosas dos enxertos. Após 55 dias, enxertos em ratos deficientes de iNOS mostraram mais infiltrados e destruição parenquimais que os tipos controle; alterações essas associadas a uma significante diminuição da contratilidade ventricular. Assim, a iNOS promove rejeição aguda mas previne a crônica. Estes efeitos opostos durante a rejeição aguda e crônica ao enxerto cardíaco são dependentes do padrão de expressão temporal e regional da iNOS durante ambas formas de rejeição ${ }^{(29)}$. Os mecanismos através dos quais a NOS media a via de regulação da falência do enxerto na rejeição aguda cardíaca são dificilmente definidos. Usando ratos desprovidos de iNOS, demonstrou-se que a via mediada pela iNOS pode promover rejeição aguda, pelo menos em parte, pela indução de morte celular apoptótica (30-32).

A precoce e persistente estimulação de iNOS em rejeição cardíaca crônica e a coincidente redução na aterosclerose e inibição de iNOS sugerem que esta indução regulatória pode contribuir para a resposta inflamatória mediando, assim, a maior tendência de aterosclerose em transplantes (33). O RNAm e a proteína da iNOS estão presentes na artéria coronária de humanos transplantados de coração com aterosclerose acelerada (AA). A iNOS expressou-se em células morfologicamente compatíveis com macrófagos na neo-íntima de 7 de 10 dos vasos examinados com transplantados com AA. Em contraste, a iNOS esteve ausente em 5 artérias coronárias nativas com aterosclerose e ausente em 2 artérias coronárias normais. Embora a iNOS expresse-se em macrófagos em AA, e supra-regulada em enxertos com aterosclerose, seu papel funcional na patogênese da aterosclerose no transplante não é claro. Sua expressão pode regular o desenvolvimento de lesão por modular a resposta aloimune precoce e/ou espessamento mio-intimal tardio. Usando um modelo experimental com rato deficiente em NOS foi possível determinar que a iNOS tem papel protetor no desenvolvimento de aterosclerose em transplantes, suprimindo o acúmulo neo-intimal de células musculares lisas $(34,35)$. A iNOS é estimulada na doença coronariana do transplante humano (DCTH), que é a maior causa de mortalidade tardia depois do transplante cardíaco. Estudos em 15 pacientes com DCTH e 10 com artérias coronárias normais, evidenciaram que as artérias normais não tiveram evidente a expressão da iNOS. Em contraste, 30 de 36 segmentos de artéria coronária com DCTH (83\%) apresentaram evidências desta isoforma da NOS. Marcadores específicos identificaram células iNOS positiva com macrófagos e células musculares lisas. Além disso, a imunoreatividade à nitrotirosina destas células foi positiva, significando atividade do peroxinitrito. Estes estudos mostraram que a proteína e o RNAm da iNOS expressam-se em artérias humanas com DCTH, onde elas estão associadas com extensiva nitração de proteínas tirosinas. Estes achados indicam que o alto débito da via do $\mathrm{NO}$ e, possivelmente o oxidante peroxi- 
nitrito, talvez estejam envolvidos no processo que leva ao desenvolvimento de DCTH ${ }^{(36)}$.

A depressão na função contrátil, durante períodos de rejeição aguda, pode ocorrer em corações transplantados (37).

Miócitos de corações rejeitados também expressam iNOS. Um defeito intrínseco, devido ao aumento da produção de NO pelos miócitos, poderia ser responsável por muitas das disfunções contráteis observadas. Como esta disfunção pode ser revertida pela aminoguanidina e azul de metileno, sugeriu-se que miócitos isolados de corações rejeitados possam ter uma reversível depressão contrátil intrínseca, a qual é mediada pela superestimulação da via óxido nítrico/cGMP dentro dos miócitos. Esta disfunção contrátil intrínseca pode ser o maior fator responsável pela reversibilidade da depressão cardíaca associada com rejeição aguda de corações transplantados (38). Além disso, o NO derivado de doador de $\mathrm{NO}$ e de endotélio coronariano mostrouse capaz de reduzir a pressão diastólica final no coração humano, especialmente durante estimulação beta-adrenérgica, por causa do começo precoce do relaxamento do ventrículo esquerdo (VE). Estudos em biópsias endomiocárdicas de 16 receptores de transplante, que estavam livres de rejeição ou vasculopatia do enxerto, mostraram que expressão gênica da iNOS miocárdica no enxerto alogênico humano influencia a resposta contrátil à estimulação beta-adrenérgica (dobutamina) através do início precoce de relaxamento do VE e redução da sua pressão diastólica final. Estes efeitos são similares aos efeitos contráteis no VE de NO derivado de doadores de NO ou de endotélio coronário ${ }^{(39)}$.

\section{COMENTÁRIOS FINAIS}

Uma verificação da Universidade de Stanford, procurou determinar se a incidência e a gravidade da DAC do transplante, detectada mediante ecografia intracoronária nos receptores de transplante de coração e pulmão, são menores que as encontradas nos receptores. Estudaram o ramo interventricular anterior mediante a ecocardiografia intracoronária em 22 receptores de transplante de coração e pulmão no momento da angiografia coronária anual de controle. Vinte e dois receptores de transplante cardíaco se igualaram aos casos com respeito ao número de anos após o transplante no estudo ecográfico, a idade do receptor e do doador, e o diagnóstico de miocardiopatia não isquêmica. Em cada grupo foi medida e calculada a média da área e índice da íntima, a classe Stanford, e a incidência da doença ao menos moderada (classe $>3$ de Stanford), comparando-as entre os 2 grupos. A área média da íntima, o índice médio da íntima, a média da classe
Stanford, e a incidência de classe 3 ou maior de Stanford foram significativamente menores no grupo receptor de transplante de coração e pulmão ${ }^{(40)}$. Esta observação é curiosa, permitindo especular se este fato decorre de uma menor manipulação do coração no transplante coração-pulmão ou, se, de alguma forma, a substituição de um pulmão doente poderia interferir na resposta inflamatória e/ou humoral do organismo receptor.

Dentro do estudo cooperativo ítalo-americano, já mencionado na introdução desta revisão, observaram-se em autópsias e na repetição do transplante, a freqüência e as características da trombose coronária em 76 aloenxertos cardíacos: 37 foram colocados durante 2 meses ou menos (precoce) e 39 durante 2 a 99 meses (tardio). Os 76 aloenxertos foram insertados em 69 pacientes: 1 em 56 pacientes, e 2 aloenxertos em 13 pacientes, 7 dos quais faleceram posteriormente e foram submetidos à autópsia. Foram examinados 140 cortes de 70 segmentos de $5 \mathrm{~mm}$ de longitude de 8 artérias coronárias epicárdicas de cada um dos 76 aloenxertos, tanto com hematoxilina-eosina como com coloração pentacrômica Movat. Somente encontrou-se trombos em uma (33\%) artéria coronária (à direita) dos 37 aloenxertos precoces, e em 24 (61\%) de 39 aloenxertos tardios. Destes últimos 39 enxertos, 29 (79\%) tiveram uma vasculopatia do aloenxerto e 24 (83\%) deles, trombose coronária. Das 312 artérias coronárias (4 maiores e 4 menores) examinadas nos 39 casos tardios, $66(21 \%)$ artérias tinham trombo. Dos 24 casos com trombo ao menos em uma artéria, encontrou-se trombos em 66 (34\%) das artérias coronárias epicárdicas examinadas: em 6 das 8 artérias em 3 pacientes; em 5 artérias em 2 pacientes; em 4 artérias em 1 paciente; e em 1 só artéria em 7 pacientes. Nas 66 artérias com trombo (24 pacientes), o trombo foi maior que $5 \mathrm{~mm}$. Os trombos nos casos tardios foram totalmente não oclusivos (mural) em 51 (77\%) das 55 artérias coronárias epicárdicas que continham trombo e totalmente oclusivo em 10 (15\%) artérias. Constou exclusivamente de canais multiluminais em 6 artérias (9\%) e combinações em 1 (2\%). Encontraram-se infartos agudos do miocárdio em 3 pacientes, todos eles com trombos oclusivos. Nas 10 artérias com trombos oclusivos sob placas ulceradas. Essas observações demonstraram que o trombo é freqüente nas artérias coronárias epicárdicas, ao menos dois meses após o transplante cardíaco, podendo significar uma disfunção endotelial tardia ou não regeneração de possíveis lesões endoteliais conseqüentes ao processo do transplante cardíaco (41).

Interessante pesquisa americana utilizou a imunohistoquímica para investigar o papel da endotelina 1 na cardiopatia coronária do transplante. Foram avaliadas a imunoreatividade e a localização 
celular da endotelina 1 em artérias coronárias humanas com arteriopatia coronária de transplante $(n=3)$ e em artérias coronárias normais $(n=10)$ mediante imunohistoquímica de marcação simples e dupla. A intensidade da imunocoloração foi determinada com um método semi-quantitativo. Foi encontrada imunoreatividade difusa e intensa da endotelina 1 em $11(85 \%)$ de 13 pacientes com arteriopatia coronária de transplante, fundamentalmente em células mioíntimas, e em menor quantidade nos macrófagos e nas células endoteliais. Ao contrário, as artérias coronárias normais somente apresentaram uma tênue imunocoloração localizada na camada endotelial. A média semiquantitativa do grau foi maior na arteriopatia coronária do transplante do que nas artérias normais $(1,8$ frente a 0,7$)$. A endotelina 1 foi encontrada com mais freqüência nas lesões ateromatosas, ricas em lipídios, que nas proliferativas, pobres em lipídios. Os novos vasos da íntima se imunotingiram constantemente para endotelina 1. Assim, estes dados sugerem que a imunorreatividade para a endotelina aumenta significativamente na cardiopatia coronária de transplante, possivelmente como conseqüência das citoquinas e os fatores de crescimento estimulantes, que se supra-regulam no estado pós-transplante. Estes resultados sugerem um possível papel deste peptídeo mitógeno na patogênese da aterosclerose de enxerto (42). Um estudo da Mayo Clinic procurou avaliar o comportamento dos níveis de endotelina e do fator atrial natriurético na evolução precoce de transplantes cardíacos em cães. A idéia inicial era verificar se o comportamento destes fatores poderia ser correlacionado com o processo de rejeição. Observou-se um progressivo aumento, tanto da endotelina como do fator atrial natriurético. Mas, como todos os cães desenvolveram insuficiência cardíaca, que cursa com o aumento dos mencionados fatores, não foi possível estabelecer, com certeza um papel de "marcador" de rejeição (Pearson, Evora, Schaff, dados não publicados, 1990) (Figura 3).

$\mathrm{Na}$ revisão sobre o papel das NOSs, ficou claro que a expressão da iNOS é a que mais se relaciona com o processo de rejeição pós-transplante cardíaco. Como em outras doenças cardiovasculares a expressão desta enzima é, aparentemente, antagônica. Ora parece ter um papel protetor, ora parece relacionar-se com processos patológicos. Um detaIhe importante pode ser extraído destas observações: no transplante cardíaco a iNOS promove rejeição aguda mas previne a rejeição crônica. Assim, a iNOS, como vários "heróis", começa como "vilã", converte-se e torna-se uma grande "heroína". Qual seria a ligação entre estes efeitos completamente opostos? Parece, pelo menos, que são mecanismos diferentes dependentes do tempo.

O uso clínico da ciclosporina (CsA) tem melho-

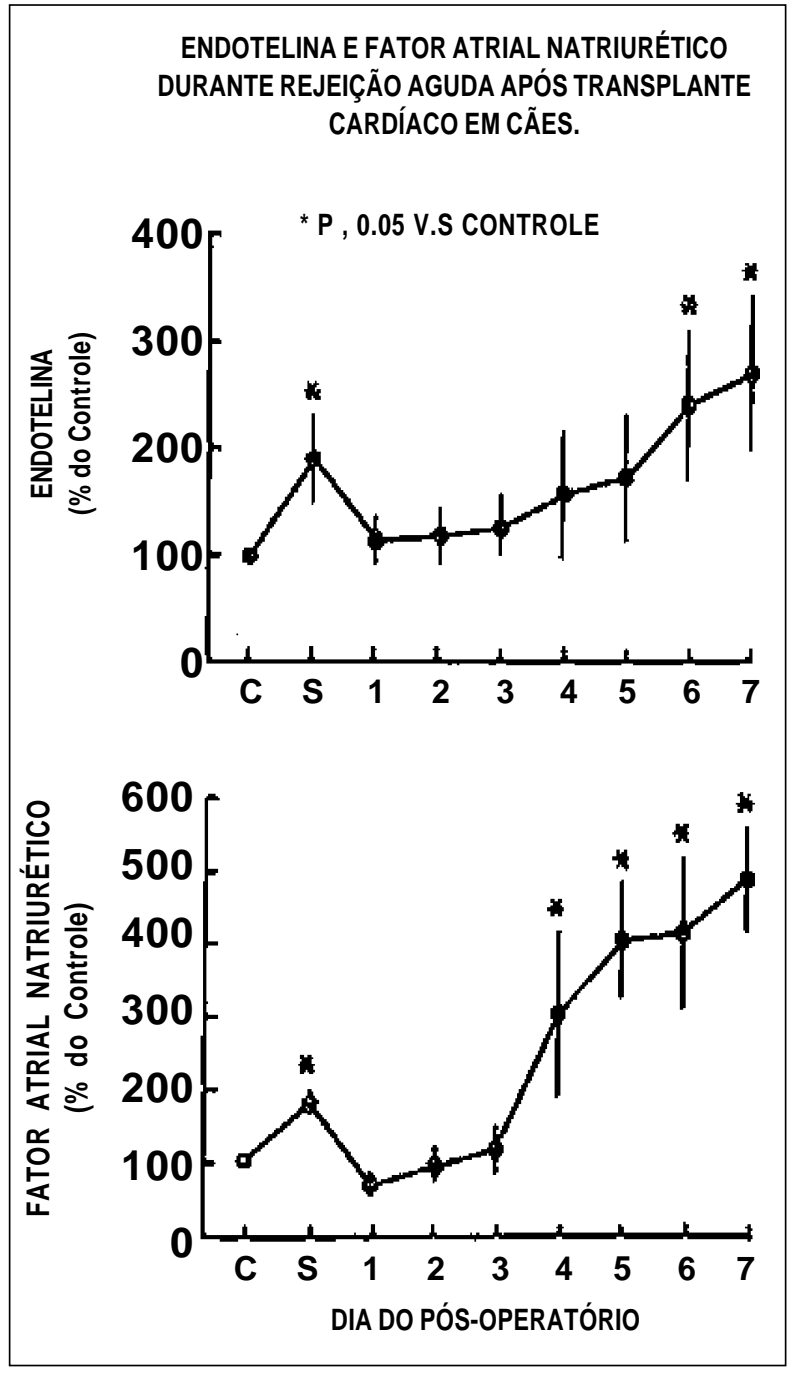

Fig. 3 - Endotelina e Fator Atrial Natriurético durante rejeição aguda de transplante cardíaco em cães (Pearson, Evora, Schaff, 1990 - Dados não publicados e apresentados com permissão).

rado muito os resultados dos transplantes de órgãos. Contudo, a CsA pode causar nefrotoxicidade e hipertensão. A administração de CsA resulta num significante aumento na pressão sangüínea arterial (PA) junto com uma diminuição na excreção urinária de Nox, sugerindo uma produção de NO deprimida. Isto acompanha-se de uma significante redução na proteína iNOS existente no rim e aorta torácica, mas não ocorre mudança no teor da proteína ecNOS. A queda na proteína iNOS renal em ratos tratados com CsA foi acompanhada por um declínio paralelo do RNAm da iNOS e atividade enzimática. Em conclusão, administração de CsA por três semanas resultou em um significante aumento na PA junto com marcada redução na excreção urinária de NOX, e expressão de iNOS renal e vascular. Estas observações sugerem que a hipertensão induzida pela CsA pode estar, em parte, relacionada com defeito 
na produção de NO. Se verdade, estratégias planejadas para restaurar a disponibilidade de NO podem suavizar a hipertensão e outras complicações vasculares da terapia com CsA (43). Estudos relacionando a disfunção endotelial em corações transplantados com a utilização da CsA e de outras drogas poderão mostrar dados interessantes e estabelecer se os seus efeitos contra a rejeição possam ser em detrimento do controle do tono e o aparecimento da DAC do transplante.

Para concluir seria importante incluir alguma informação geral sobre terapêutica genética e tentar analisar as particularidades da expressão da NOS de acordo com o tipo de doença cardiovascular. A terapêutica genética envolve a transferência de um gene funcional para células hospedeiras com a finalidade de corrigir a disfunção de um gene específico ou aliviar os sintomas da doença. Para a transferência gênica no sistema cardiovascular, a utilização de adenovírus vetores vem a ser o recurso mais eficiente. Recentemente, a transferência e expressão funcional de genes recombinantes da NOS para o cérebro e leitos vasculares tem sido demonstrada tanto in vitro como in vivo. Estudos têm demonstrado, com sucesso, a transferência de ecNOS RNAm em artérias coronárias de porcos como se verifica pela localização histoquímica de proteína recombinante com um aumento da liberação de NO, demonstrada pelo aumento da produção de nitrito e alteração da função vasomotora. Apesar da possibilidade da transferência gênica está sendo demonstrada em modelos animais. Os vetores atualmente disponíveis apresentam grandes limitações técnicas e de segurança, as quais precisam ser resolvidas antes de se tentar a terapêutica genética com a NOS em humanos para o tratamento de doenças vasculares proliferativas. Mais de 100 protocolos têm sido propostos para a terapêutica genética em humanos nos Estados Unidos, mas nenhum resultado efetivo tem sido apresentado neste campo. As deficiências da terapêutica genética resultam, principalmente, da falta de vetores eficientes de transferência gênica. Acresça-se que, quanto mais longínqua se encontre a terapêutica genética somática, mais difícil será o controle das doenças sistêmicas, mesmo após o desenvolvimento de sistemas vetores mais poderosos. Entretanto, doenças localizadas poderão ser melhor controladas pela terapêutica genética. A este respeito, as doenças cardiovasculares serão alvos promissores para a terapêutica gênica $(44,45)$.

\section{RBCCV 44205-487}

Viaro F \& Evora PRB - Expression of nitric oxide synthases in coronary artery disease after heart transplantation. Rev Bras Cir Cardiovasc 2000; 15 (1): 55-65.

ABSTRACT: A major complication that can limited the evolution of a cardiac transplantation over the long term is the development of accelerated coronary arteriosclerosis. This form of coronary disease is different from the atherosclerotic coronary disease of patients not submitted to cardiac transplantation. Current evidence obtained by intravascular ultrasound, has demonstrated that the occurrence of a precocious endothelial dysfunction, mainly mediated by the inducible isoform of the nitric oxide synthase (iNOS) expression, is associated with the development of atherosclerosis in cardiac allografts during the first year of the transplant. This review was developed starting with basic concepts (description of the enzyme and its known isoforms; a brief comparison between them), reviewing the coronary endothelial dysfunction after cardiac transplantation, from the specific point of view of the NOS enzymatic function. In cardiac transplantation iNOS promotes acute rejection but prevents chronic episodes. The relationship between these opposing effects remains unknown we only know that they are different mechanisms which are time-dependent.

DESCRIPTORS: Nitro-oxide synthese, metabolism. Endothelium, vascular, enzymology. Heart transplantation, physiology. Graft rejection, enzymology.

\section{REFERÊNCIAS BIBLIOGRÁFICAS}

1 Billingham M E - Cardiac transplant atherosclerosis. Transplant Proc 1987; 19 (4 suppl. V): 19-25.

2 Davis S F, Yeung A C, Meredith I T et al. - Early endothelial dysfunction predicts the development of transplant coronary artery disease at 1 year posttransplant. Circulation 1996; 93: 457-62.

3 Arbustini E \& Roberts W C - Morphological observations in the epicardial coronary arteries and their surroundings late after cardiac transplantation. $A m \mathrm{~J}$ Cardiol 1996; 78: 814-20. 
4 Cooke J P \& Dzau V J - Nitric oxide synthase: role in the genesis of vascular disease. Annu Rev Med 1997; 48: 489-509.

5 Rees D D, Palmer R M, Moncada S - Role of endotheliumderived nitric oxide in the regulation of blood pressure. Proc Natl Acad Sci USA 1989; 86: 3375-8.

6 Vallance P, Collier J, Moncada S - Effects of endotheliumderived nitric oxide on peripheral arteriolar tone in man. Lancet 1989; 2: 997-1000.

7 Kilbourn R G, Szabó C, Traber D L - Beneficial versus detrimental effects of nitric oxide synthase inhibitors in circulatory shock: lessons learned from experimental and clinical studies. Shock 1997; 7: 235-46.

$8 \quad$ Wang Y \& Marsden P A - Nitric oxide synthases: gene structure and regulation. Adv Pharmacol 1995; 34: 71-90.

9 Seccombe J F \& Schaff H V - Vasoactive factors produced by the endothelium: physiology and surgical implications. Austin: R.G.Landes Company, 1994:10.

10 Schmidt H H, Pollock J S, Nakane M, Forstermann U, Murad F - Ca2+/calmodulin-regulated nitric oxide synthases. Cell Calcium 1992; 13: 427-34.

11 Fleming I \& Busse R - NO:the primary EDRF. J Mol Cell Cardiol 1999; 31: 5-14.

12 Forstermann U, Closs El, Pollock JS et al. - Nitric oxide synthase isozymes: characterization, purification, molecular cloning, and functions. Hypertension 1994; 23:(6 Pt 2):1121-31.

13 Fukuchi M, Hussain S N, Giaid A - Heterogeneous expression and activity of endothelial and inducible nitric oxide synthases in end-stage human heart failure. Circulation 1998; 98: 132-9.

14 Cannon P J, Yang X, Szabolcs M, Ravalli S, Sciacca R $R$, Michler R E - The role of inducible nitric oxide synthase in cardiac allograft rejection. Cardiovasc Res 1998; 38: 6-15.

15 Forstermann $U$ \& Kleinert $\mathrm{H}$ - Nitric oxide synthase: expression and expressional control of the three isoforms. Naunyn Schmiedebergs Arch Pharmacol 1995; 352: 351-64.

16 Kiechle $\mathrm{F} L$ \& Malinski T - Indirect detection of nitric oxide effects: a review. Ann Clin Lab Sci 1996; 26: 501-11.

17 Évora P R B, Garcia L V, Nobre F, Viaro F - Endotélio e óxido nítrico: do laboratório à prática clínica. $M e$ dicina 1999; 32: 65-81.

18 Miyazaki $\mathrm{H}$, Matsuoka $\mathrm{H}$, Cooke J P et al. - Endogenous nitric oxide synthase inhibitor: a novel marker of atherosclerosis. Circulation 1999; 99: 1141-6.

19 Kroncke K D, Fehsel K, Kolb-Bachofen V - Inducible nitric oxide synthase in human diseases. Clin Exp Immunol 1998; 113: 147-56.

20 Ursell P C \& Mayes M - Anatomic distribution of nitric oxide synthase in the heart. Int $J$ Cardiol 1995; 50: 217-23.

21 Balligand J L \& Cannon P J - Nitric oxide synthases and cardiac muscle: autocrine and paracrine influences. Arterioscler Thromb Vasc Biol 1997; 17: 1846-58.

22 Yang X, Chowdhury N, Cai B et al. - Induction of myocardial nitric oxide synthase by cardiac allograft rejection. J Clin Invest 1994; 94: 714-21.

23 Worrall N K, Misko T P, Botney M D et al. - Time course and cellular localization of inducible nitric oxide synthases expression during cardiac allograft rejection. Ann Thorac Surg 1999; 67: 716-22.

24 Paul L C, Myllarniemi M, Muzaffar S, Benediktsson H Nitric oxide synthase inhibition is associated with decreased survival of cardiac allografts in the rat. Transplantation 1996; 62: 1193-5.

25 Worrall N K, Misko T P, Sullivan P M, Hui J J, Ferguson $\mathrm{T} B \mathrm{Jr}$ - Inhibition of inducible nitric oxide synthase attenuates established acute cardiac allograft rejection. Ann Thorac Surg 1996; 62: 378-85.

26 Worrall N K, Chang K, Suau G M et al. - Inhibition of inducible nitric oxide synthase prevents myocardial and systemic vascular barrier dysfunction during early cardiac allograft rejection. Circ Res 1996; 78: 769-79.

27 Worrall N K, Misko T P, Sullivan P M, Hui J J, Rodi C $P$, Ferguson T B Jr - Corticosteroids inhibit expression of inducible nitric oxide synthase during acute cardiac allograft rejection. Transplantation 1996; 61: 324-8.

28 Cai B, Roy D K, Sciacca R, Michler R E, Cannon P J - Effects of immunosuppressive therapy on expression of inducible nitric oxide synthase (iNOS) during cardiac allograft rejection. Int J Cardiol 1995; 50: 243-51.

29 Koglin J, Glysing-Jensen T, Mudgett J S, Russell M E - NOS2 mediates opposing effects in models of acute and chronic cardiac rejection: insights from NOS2knockout mice. Am J Pathol 1998; 153: 1371-6.

30 Szabolcs M, Michler RE, Yang $X$ et al. - Apoptosis of cardiac myocytes during cardiac allograft rejection: relation to induction of nitric oxide synthase. Circulation 1996; 94: 1665-73.

31 Szabolcs M J, Ravalli S, Minanov O, Sciacca R R, Michler R E, Cannon P J - Apoptosis and increased expression of inducible nitric oxide synthase in human allograft rejection. Transplantation 1998; 65: 804-12.

32 Koglin J, Granville DJ, Glysing-Jensen T et al. Attenuated acute cardiac rejection in NOS2 -/recipients correlates with reduced apoptosis. Circulation 1999; 99: 836-42. 
33 Russell M E, Wallace A F, Wyner L R, Newell J B, Karnovsky $\mathrm{M} \mathrm{J}$ - Upregulation and modulation of inducible nitric oxide synthase in rat cardiac allografts with chronic rejection and transplant arteriosclerosis. Circulation 1995; 92: 457-64.

34 Lafond-Walker A, Chen C L, Augustine S, Wu T C, Hruban $\mathrm{R} \mathrm{H}$, Lowenstein $\mathrm{C} \mathrm{J}$ - Inducible nitric oxide synthase expression in coronary arteries of transplanted human hearts with accelerated graft arteriosclerosis. Am J Pathol 1997; 151: 919-25.

35 Koglin J, Glysing-Jensen T, Mudgett J S, Russell M E Exacerbated transplant arteriosclerosis in inducible nitric oxide-deficient mice. Circulation 1998; 97: 2059-65.

Ravalli S, Albala A, Ming M et al. - Inducible nitric oxide synthase expression in smooth muscle cells and macrophages of human transplant coronary artery disease. Circulation 1998; 97: 2338-45.

37 Lewis N P, Tsao P S, Rickenbacher P R et al. - Induction of nitric oxide synthase in the human cardiac allograft is associated with contractile dysfunction of the left ventricle. Circulation 1996; 93: 720-9.

38 Ziolo M T, Dollinger S J, Wahler G M - Myocytes isolated from rejecting transplanted rat hearts exhibit reduced basal shortening which is reversible by aminoguanidine. J Mol Cell Cardiol 1998; 30: 1009-17.

39 Paulus W J, Kastner S, Pujadas P, Shah A M, Drexler $H$, Vanderheyden M - Left ventricular contractile effects of inducible nitric oxide synthase in the human allograft. Circulation 1997; 96: 3436-42.

$40 \operatorname{Lim} \mathrm{T}$ T, Botas J, Ross $\mathrm{H}$ et al - Are heart-lung transplant recipients protected from developing transplant coronary artery disease? A case-matched intracoronary ultrasound study. Circulation 1996; 94: 1573-7.

41 Arbustini E, Dal Bello B, Morbini P et al. - Frequency and characteristics of coronary thrombosis in the epicardial coronary arteries after cardiac transplantation. $\mathrm{Am} \mathrm{J}$ Cardiol 1996; 78: 795-800.

42 Ravalli S, Szabolcs M, Albala A, Michler R E, Cannon $P \mathrm{~J}$ - Increased immunoreactive endothelin-1 in human transplant coronary artery disease. Circulation 1996; 94: 2096-102.

43 Vaziri N D, Ni Z, Zhang Y P, Ruzics E P, Maleki P, Ding $Y$ - Depressed renal and vascular nitric oxide synthase expression in cyclosporine-induced hypertension. Kidney Int 1998; 54: 482-91.

44 Chen A F, O'Brien T, Katusic Z S - Transfer and expression of recombinant nitric oxide synthase genes in the cardiovascular system. Trends Pharmacol Sci 1998; 19: 276-86.

45 Cable D G, O'Brien T, Kullo I J, Schwartz R S, Schaff H V, Pompili V J - Expression and function of a recombinant endothelial nitric oxide synthase gene in porcine coronary arteries. Cardiovasc Res 1997; 35: 553-9. 